\title{
Pemberdayaan Petani Sayuran di Desa Wolofeo, Kecamatan Detusoko, Kabupaten Ende
}

\author{
Yustina Maria Silvia Wonga Puu ${ }^{1}$, Agustinus J.P. Ana Saga ${ }^{1}$, Baltasar Taruma Djata ${ }^{2}$, \\ Charly Mutiara ${ }^{1}$ * \\ ${ }^{1}$ Fakultas Pertanian, Universitas Flores, Ende, Nusa Tenggara Timur \\ ${ }^{2}$ Fakultas Ekonomi, Universitas Flores, Ende, Nusa Tenggara Timur \\ "Corresponding author: charlyinter1988@gmail.com
}

\begin{abstract}
ABSTRAK
Kendala yang dihadapi oleh para petani di Desa Wolofeo adalah produksi sayuran yang tidak pernah meningkat walaupun pemakaian pupuk anorganik terus meningkat setiap musim tanam. Karena itu dilakukan kegiatan pemberdayaan dengan tujuan untuk meningkatkan pengetahuan para petani terkait pola tanam, pupuk organik, hama dan penyakit serta penjualan hasil pertanian. Kegiatan pemberdayaan ini melibatkan 30 petani dari desa Wolofeo dengan cara menyuluh dan melatih. Materi yang diberikan kepada petani untuk kegiatan menyuluh yaitu tentang pola tanam, hama dan penyakit tanaman, serta pemasaran hasil pertanian. Sedangkan pelatihan yang diberikan yaitu tentang mikroorganisme lokal, pupuk organik dan perangkap lalat buah. Dari kegiatan pemberdayaan diketahui bahwa pengetahuan para petani tentang pola tanam, hama dan penyakit pada tanaman, pemasaran hasil pertanian, mikroorganisme lokal, serta pupuk organik dan perangkap lalat buah semakin meningkat seperti yang ditunjukkan dari hasil post-test. Hasil pre-test yang diperoleh para petani pada penyuluhan adalah 47,22 sedangkan post-test adalah 70,4. Pada kegiatan pelatihan diperoleh hasil pre-test 36,74 sedangkan post-test 64,2 .
\end{abstract}

Kata kunci: pemberdayaan, petani, sayuran

\section{ABSTRACT}

The obstacle faced by farmers in Wolofeo Village is that vegetable production has never increased even though the use of inorganic fertilizers continues to increase every planting season. Therefore, empowerment activities are carried out with the aim of increasing farmers' knowledge regarding cropping patterns, organic fertilizers, pests, and diseases as well as the sale of agricultural products. This empowerment activity involved 30 farmers from Wolofeo village by providing counseling and training. Materials given to farmers for extension activities include cropping patterns, plant pests and diseases, and marketing of agricultural products. Meanwhile, the training provided was on local microorganisms, organic fertilizers, and fruit fly traps. From the empowerment activities, it is known that the knowledge of farmers about cropping patterns, pests and diseases in plants, marketing of agricultural products, local microorganisms, as well as organic fertilizers and fruit fly traps has increased as shown in the post-test results. The pre-test results obtained by the farmers at extension services were 47.22 while the post-test results were 70.4. In the training activities, the pre-test results were 36.74 while the post-test results were 64.2.

Keywords: empowerment, farmer, vagetables

\section{PENDAHULUAN}

Salah satu desa di Kabupaten Ende tepatnya di Kecamatan Detusoko yang mempunyai potensi besar di bidang pertanian adalah Desa Wolofeo. Daerah ini memiliki lahan persawahan seluas 204 ha, perkebunan yang dikelola masyarakat seluas 56 ha, dikelola pemerintah seluas 18 ha dan dikelola swasta seluas 15 ha. Potensi lahan yang cukup luas ini menyebabkan berbagai aktivitas budidaya pertanian berlangsung pada lahan-lahan tersebut. Salah satu budidaya pertanian yang banyak dilaksanakan adalah budidaya sayur-sayuran. 
Desa Wolofeo mempunyai beberapa komoditas pertanian yang melimpah. Komoditas yang melimpah ini diantaranya adalah cabai, sawi hijau, sawi putih, terung, kacang panjang dan kubis. Berdasarkan data dari Badan Pusat Statistik Kabupaten Ende (2019) diketahui bahwa Desa Wolofeo merupakan penghasil terbanyak sawi hijau di Kabupaten Ende dan urutan keduanya adalah kubis. Walaupun mempunyai komoditas pertanian yang melimpah, namun pendapatan petani dari hasil tersebut selalu menurun. Berdasarkan wawancara dengan para petani, hal ini dikarenakan mereka harus meningkatkan penggunaan pupuk dan pestisida anorganik setiap musim tanam namun tidak diikuti dengan peningkatan produksi tanaman.

Hasil survei di lapangan menunjukkan bahwa salah satu penyebab permasalahan adalah serangan hama dan penyakit dari Plutella xylostella L., bercak daun serta hama lalat buah. Penyebab lainnya adalah pola tanam monokultur yang diterapkan para petani. Pola tanam yang kurang tepat berdampak pada kondisi tanah dan tanaman yang kurang subur (Fowo, 2007; Mahriani \& Wahditiya Adriyani, 2019). Selain itu, tanah yang kurang subur ini dikarenakan aktivitas pertanian yang intensif dan hanya memupuk menggunakan pupuk anorganik. Hasil penelitian Rosliana et al. (2010) menyebutkan bahwa pertanian intensif dan pemakaian pupuk anorganik berlebihan mengakibatkan penurunan kesuburan tanah serta produksi tanaman. Hasil penelitian Kaya (2014) menunjukkan bahwa penggunaan pupuk anorganik tanpa adanya tambahan pupuk organik menyebabkan $\mathrm{pH}$ tanah menjadi lebih rendah dan ketersedian unsur hara semakin rendah.

Berdasarkan uraian-uraian tersebut, maka kegiatan pemberdayaan bagi petani sayuran di Desa Wolofeo penting untuk dilaksanakan. Pemberdayaan ini diharapkan dapat meningkatkan pengetahuan para petani terkait pola tanam, pupuk organik, hama dan penyakit serta pemasaran hasil pertanian.

\section{METODE}

Kegiatan pemberdayaan petani sayuran dilakukan di Desa Wolofeo Kecamatan Detusoko Kabupaten Ende. Kegiatan ini mulai dilaksanakan 30 Juli 2019-10 September 2019. Sebelum pemberdayaan dimulai dilaksanakan survei lapangan, mempersiapkan alat dan bahan untuk pelaksanaan kegiatan pelatihan dan penyuluhan. Peserta yang terlibat dari pihak Universitas Flores sebanyak 24 orang yang terdiri dari dosen dan mahasiswa/i. Sedangkan dari pihak Desa Wolofeo terdiri dari 30 orang petani.

Kegiatan pemberdayaan kepada masyarakat dilakukan dengan cara penyuluhan dan pelatihan. Pelatihan yang diberikan melibatkan para petani sacara langsung sehingga pengetahuan yang diberikan lebih cepat dimengerti (Sankaran \& Demangeot, 2017; Secundo et al., 2017). Kegiatan penyuluhan dan pelatihan diketahui tingkat keberhasilannya dengan melakukan pre-test dan post-test. Soal test yang diberikan sebanyak 20 soal berbentuk pilihan. Pertanyaan-pertanyaan di dalam pretest dibuat sederhana dengan pertimbangan latar belakang pendidikan peserta. Materi soal meliputi pengetahuan tentang pola tanam, hama dan penyakit tanaman, pemasaran hasil pertanian, mikroorganisme lokal, pupuk organik, dan lalat buah serta perangkapnya. Pre-test yang dilakukan ini bertujuan agar mengetahui pengetahuan awal peserta kegiatan pemberdayaan yang dilakukan. Selanjutnya, pada akhir kegiatan dilakukan post-test. Hasil pretest dan posttest ditampilkan dalam bentuk grafik.

Tahap kedua yaitu penyuluhan, dengan kegiatan-kegiatannya adalah penyuluhan tentang pola tanam, hama dan penyakit tanaman serta pemasaran hasil pertanian. Saat ini pola tanam yang diterapkan petani di Wolofeo adalah monokultur. Karena itu penyuluhan dilakukan dengan memberikan materi kelebihan dan kekurangan penerapan pola tanam yang ada terutama monokultur. Selain itu, juga diberikan informasi terkait langkah-langkah meminimalkan kekurangan pola tanam tersebut. Penyuluhan tentang hama dan penyakit tanaman berfokus pada komoditi sayur-sayuran yang ada di Desa Wolofeo. Sedangkan penyuluhan terkait pemasaran hasil pertanian, petani diajarkan cara meningkatkan nilai jual barang dan mencari pasar yang sesuai dengan peningkatan nilai jual barang tersebut.

Pelatihan yang dilakukan berikutnya adalah pembuatan mikroorganisme lokal, pupuk organik, serta perangkap lalat buah untuk tanaman cabai. Pelatihan pembuatan mikroorganisme lokal diawali dengan pemberian informasi tentang manfaat mikroorganisme lokal (mol). Setelah itu, alat dan bahan dipersiapkan oleh para petani dan penyuluh, lalu diadakan pelatihan pembuatan 
mol. Pelatihan pembuatan pupuk organik, para petani diberi penjelasan terlebih dahulu tentang kelebihan dan kekurangan pupuk organik, serta alat dan bahannya. Setelah itu alat dan bahan dipersiapkan, lalu pelatihan dilakukan dengan mengutamakan partisipasi aktif dari para petani.

Kegiatan pelatihan selanjutnya yaitu pembuatan perangkap lalat buah. Kegiatan ini dilakukan di kebun cabai salah satu petani dan diawali dengan pemasangan perangkap petrogenol. Pemasangan perangkap menggunakan botol bekas dan dipasang di seluruh kebun.

\section{HASIL DAN PEMBAHASAN}

Penyuluhan dan pelatihan telah dilakukan kepada para petani di Desa Wolofeo. Materi untuk penyuluhan yaitu pola tanam, hama dan penyakit tanaman, serta pemasaran hasil pertanian. Sedangkan untuk pelatihan dilakukan pembuatan mikroorganisme lokal (mol), pupuk organik serta perangkap lalat buah.

\section{Penyuluhan}

Penyuluhan tentang pola tanam bertujuan agar para petani memahami kelebihan dan kekurangan masing-masing jenis pola tanam. Tujuan lainnya adalah agar para petani mengetahui dampak negatif yang terjadi karena penerapan pola tanam terhadap kesuburan tanah dan tanaman. Penerapan pola tanam terkait dengan pengaturan jarak tanam. Jarak tanam yang tepat akan memberikan hasil pertanian yang optimal (Nai \& Fowo, 2019). Salah satu jenis pola tanam yang dapat memberikan hasil yang optimal adalah tumpang sari. Penerapan pola tanam ini dapat memberikan pengaruh terhadap peningkatan hasil tanaman serta kesuburan tanah (Mauidzotussyarifah et al., 2018; Mutiara \& Bolly, 2019).

Kegiatan penyuluhan tentang pola tanam melibatkan para dosen dan mahasiswa dari Universitas Flores serta para petani. Gambar 1 terlihat proses penyuluhan yang berlangsung tentang kelebihan dan kekurangan pola tanam monokultur yang telah dilaksankan para petani. Selain itu, para penyuluh juga memberikan informasi terkait langkah-langkah yang dapat dilakukan untuk meminimalisir kekurangan pola tanam monokultur.

Dalam kegiatan penyuluhan tentang hama dan penyakit, petani diberikan informasi secara lengkap. Hal ini dapat diamati pada gambar 2. Informasi tersebut bermanfaat untuk para petani dalam merencanakan pencegahan dan pengendalian yang efektif (Septariani et al., 2019). Informasi tersebut sejalan dengan kegiatan pengabdian yang telah dilakukan (Pu'u et al., 2019).

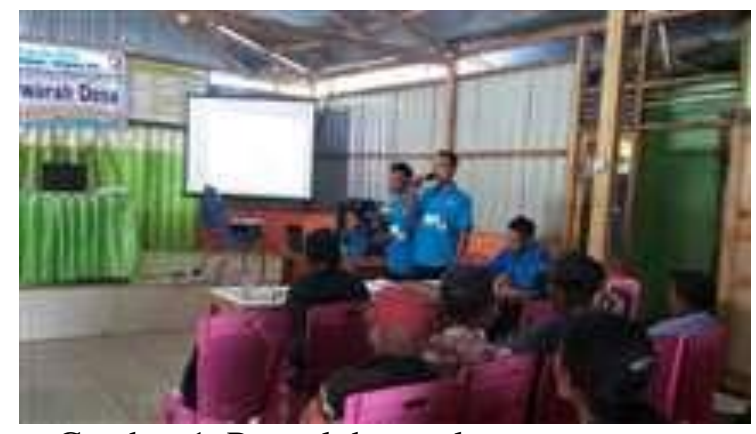

Gambar 1. Penyuluhan pola tanam sayuran

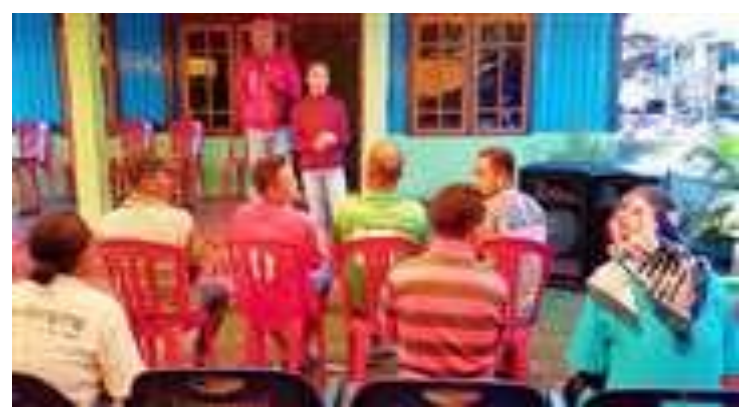

Gambar 2. Penyuluhan hama dan penyakit tanaman

Kegiatan penyuluhan pemasaran memberikan gambaran kepada petani tentang teknik-teknik pemasaran yang baik. Hal tersebut bertujuan agar produknya dapat bersaing di pasaran dengan harga yang menguntungkan. Hasil kegiatan ini membuat petani paham pentingnya pengelolan Bumdes di desa yang dapat menerima hasil dan menyediakan pasar serta pembeli. Penyuluhan tentang pemasaran bertujuan agar dapat meningkatkan pendapatan dari para petani.

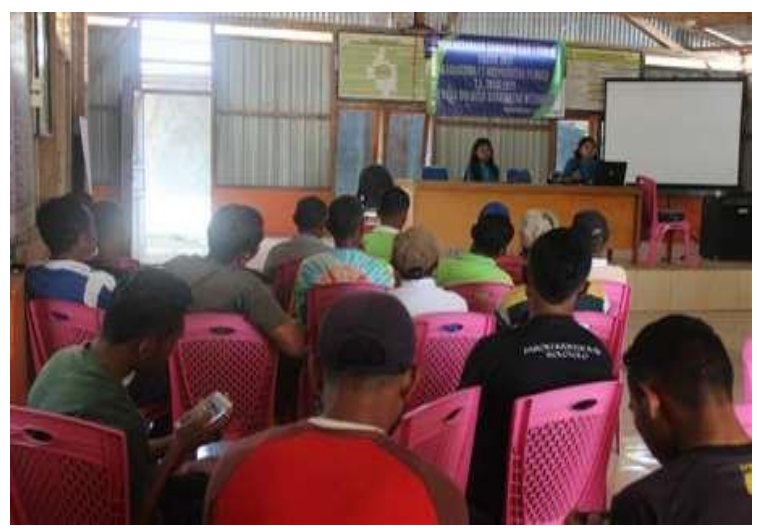

Gambar 3. Penyuluhan penjualan hasil pertanian 
Pada Gambar 3, terlihat bahwa penjelasan tentang pemasaran hasil pertanian sangat dicermati dengan serius oleh para peserta yang hadir. Pemberian informasi tentang pemasaran atau penjualan kepada masyarakat telah dilakukan oleh Ulfa et al. (2020).

\section{Pelatihan}

Kegiatan pelatihan pembuatan mikroorganisme lokal (mol) dilakukan di salah satu dusun di Desa Wolofeo. Para petani terlibat langsung dalam kegiatan tersebut yang ditunjukkan Gambar 4. Mikroorganisme lokal ini nantinya dapat dimanfaatkan petani dalam pembuatan pupuk organik. Selain itu dapat juga langsung diaplikasikan ke lahan pertanian untuk meningkatkan jumlah mikroorganisme di dalam tanah (Mursalim et al., 2018; Tambunan, 2018).

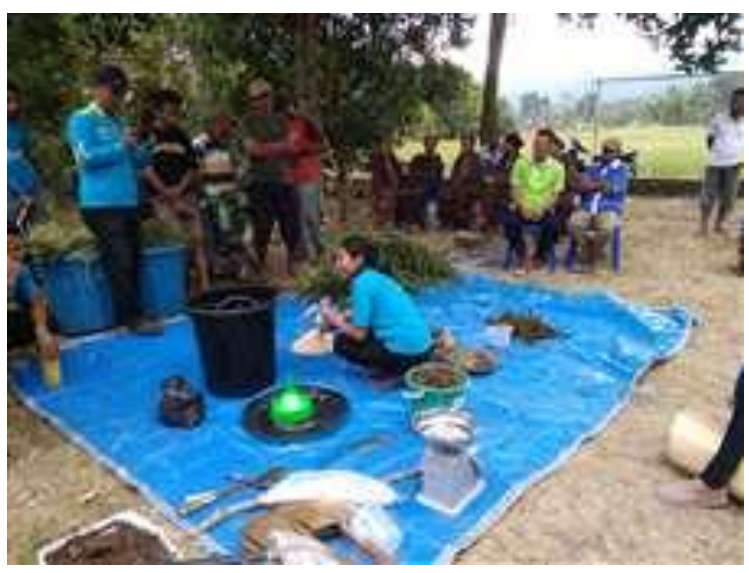

Gambar 4. Pelatihan pembuatan mikroorganisme lokal

Mikroorganisme lokal (mol) mempunya kandungan yang berbeda-beda. Hal ini terkait dengan sumber bahan yang digunakan dalam pembuatan mol (Jeksen \& Mutiara, 2018; Marsiningsih et al., 2015; Pulupi, 2015). Kegiatan pelatihan pembuatan pupuk organik telah dilakukan di Desa Wolofeo dengan melibatkan para petani.Dari Gambar 5 tampak para petani terlibat secara aktif dalam pembuatan pupuk tersebut.

Pelatihan pembuatan pupuk organik didahului dengan pemberian informasi kepada petani terkait pengaruh positif dan negatif dari pupuk organik dan anorganik. Pemakaian pupuk anorganik yang berlebihan dapat mencukupi kebutuhan hara dengan cepat, namun kesuburan menjadi menurun (Kaya, 2014; Rosliana et al., 2010). Kegiatan pelatihan selanjutnya tentang pembuatan perangkap bagi hama lalat buah. Penanganan yang telah dilakukan petani adalah dengan menyemprotkan pestisida anorganik ke bagian tanaman yang terserang. Dengan adanya pelatihan ini, diharapkan dapat mengurangi pemakaian pestisida anorganik dan hama yang menyerang tanaman (Shahabuddin, 2012; Susanto et al., 2018). Pada Gambar 6, terlihat seorang mahasiswa yang mempraktekan pembuatan perangkap lalat buah.

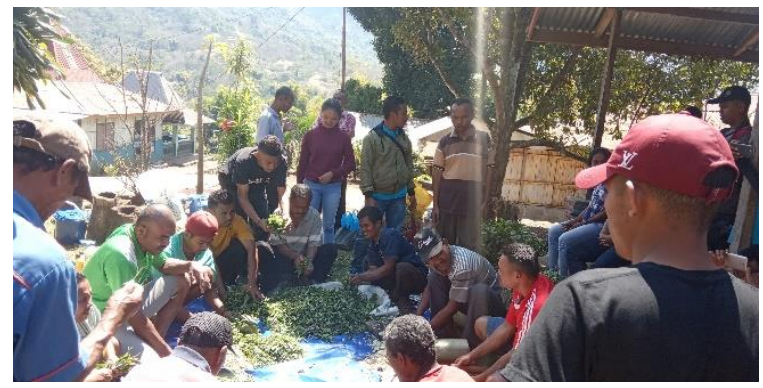

Gambar 5. Pembuatan Pupuk Organik

\section{Evaluasi kegiatan}

Keseluruhan program kegiatan yang telah dilaksanakan dievalusi pada awal dan akhir kegiatan melalui pretest dan posttest.Hasil pretest dan posttest terhadap kegiatan penyuluhan dan pelatihan yang telah dilakukan menunjukkan adanya peningkatan sebesar $23,18 \%$ dan $27,46 \%$, seperti yang ada pada Gambar 7 dan 8 . Hasil pre-test yang diperoleh para petani untuk penyuluhan adalah 47,22 sedangkan post-test 70.4. Pada kegiatan pelatihan diperoleh hasil pre-test 36,74 sedangkan post-test 64,2. Peningkatan ini terkait dengan pengetahuan petani terhadap materi penyuluhan yang diberikan tentang pola tanam, hama dan penyakit tanaman, dan pemasaran hasil pertanian, serta pelatihan tentang pembuatan mikroorganisme lokal, pupuk organik dan perangkap lalat buah.

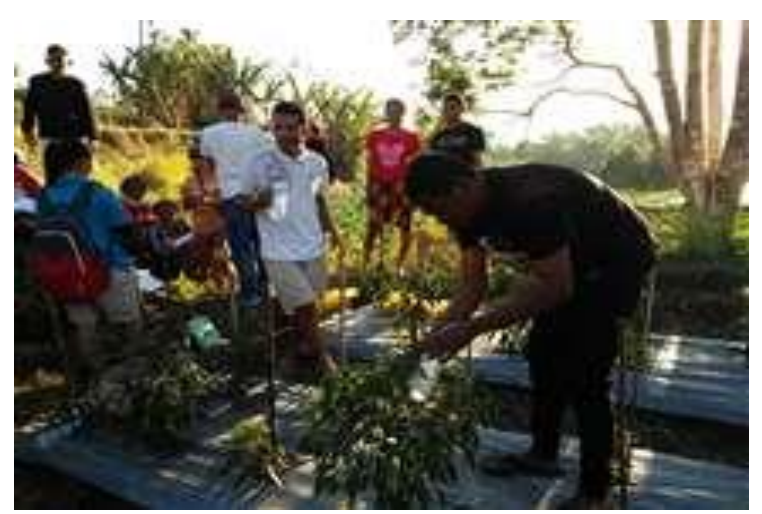

Gambar 6. Pembuatan perangkap lalat buah

Kegiatan penyuluhan yang dilakukan kepada petani dapat dimengerti dengan baik 
seperti yang terlihat pada hasil post-test. Hal ini dikarenakan penyuluhan yang diberikan kepada para petani bukan hanya satu arah tapi terdapat umpan balik. Kegiatan penyuluhan dengan adanya interaksi atau umpan balik ini meningkatkan antusias petani untuk terlibat lebih aktif (Ban \& Hawkins, 1999). Sedangkan pada kegiatan pelatihan, dapat dimengerti dengan baik oleh para petani karena mereka terlibat sacara langsung (Ban \& Hawkins, 1999; Sankaran \& Demangeot, 2017; Secundo et al., 2017).

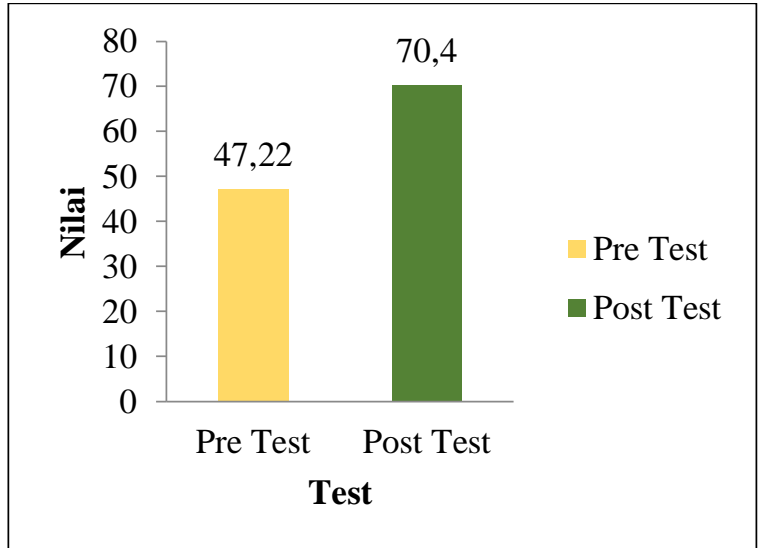

Gambar 7. Hasil pre-test dan post-test kegiatan penyuluhan

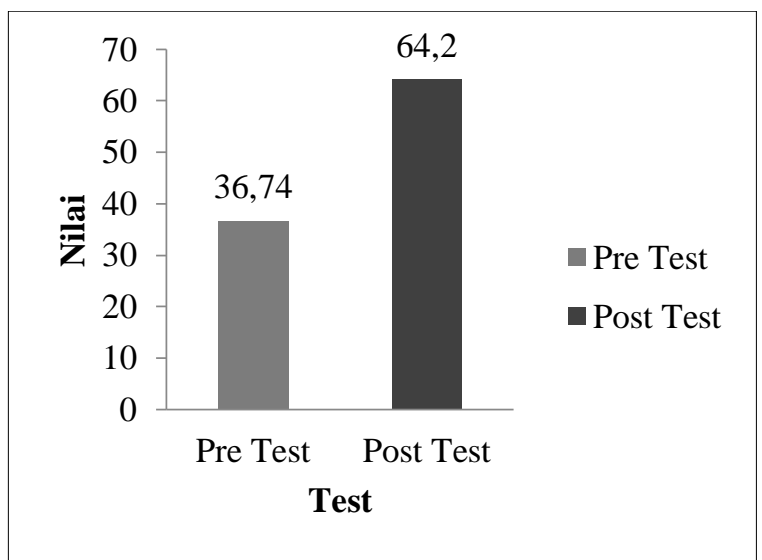

Gambar 8. Hasil pre-test dan post-test kegiatan pelatihan

Selain dari hasil post-test, keberhasilan kegiatan pemberdayaan ini dapat terlihat langsung dari antusias para petani setelah kegiatan berakhir. Para petani mulai antusias untuk menyiapkan bahan-bahan di sekitarnya yang diperlukan untuk membuat pupuk organik. Mereka juga tertarik untuk membuat mol, sehingga dapat mempercepat proses pembuatan pupuk organik. Hal tersebut berdampak pada peningkatan ketersediaan pupuk organik dan penggunaan pupuk anorganik yang mulai berkurang dosisnya. Hasil kegiatan dapat dilihat dari beberapa petani sudah mulai mengaplikasikan pupuk organik yang telah selesai dibuat saat kegiatan pemberdayaan.

\section{KESIMPULAN}

Simpulan yang dapat diambil dari kegiatan pemberdayaan ini adalah pengetahuan petani yang semakin baik tentang pola tanam, hama dan penyakit pada tanaman, pemasaran hasil pertanian, mikroorganisme lokal, pupuk organik dan perangkap lalat buah. Membaiknya pengetahuan petani tersebut dapat dilihat dari post-test yang telah dilakukan. Hasil pre-test yang diperoleh para petani adalah 47,22 sedangkan post-test 70,4. Pada kegiatan pelatihan diperoleh hasil pre-test 36,74 sedangkan post-test 64,2. Kegiatan ini berdampak langsung pada peningkatan ketersediaan pupuk organik dan penggunaan pupuk anorganik yang mulai berkurang dosisnya.

\section{UCAPAN TERIMA KASIH}

Pada kesempatan ini penulis berterima kasih kepada DPRM Kemenristekdikti karena kegiatan pemberdayaan ini telah dibiayai.

\section{DAFTAR PUSTAKA}

Badan Pusat Statistik Kabupaten Ende. (2019). Kabupaten Ende Dalam Angka (p. 448). Badan Pusat Statistik Kabupaten Ende.

Ban, A. W. van den, \& Hawkins, H. S. (1999). Penyuluhan Pertanian (13th ed.). Kanisius.

Fowo, K. Y. (2007). Interval waktu tanam kacang tanah (Archis hipogaea L.) dan jagung pulut (Zea mays caratina kulesh) pada pola tanam tumpang sari terhadap pertumbuhan dan hasil kacang tanah di lahan kering. Agrica, 11(1), 1-9.

Jeksen, J., \& Mutiara, C. (2018). Pengaruh sumber bahan organik yang berbeda terhadap kualitas pembuatan mikroorganisme lokal (MOL). Agrica, 11(1), 60-72. https://doi.org/https: //doi.org/10.37478/agr.v11i1.23

Kaya, E. (2014). Pengaruh pupuk organik dan pupuk NPK terhadap $\mathrm{pH}$ dan K-tersedia tanah serta serapan-K, pertumbuhan, dan hasil padi sawah (Oryza sativa L). Buana Sains, 14(2), 113-122. 
Mahriani, \& Wahditiya Adriyani. (2019). Pengaruh pola tanam terhadap tingkat kesuburan tanah dan produktivitas tanaman padi (Oryza sativa L.). Jurnal Agrotan, 5(2).

Marsiningsih, N. W., Gede, S. A. . N., \& Sri, S. N. W. (2015). Analisis kualitas larutan mol (mikroorganisme lokal) berbasis ampas tahu. Agroekoteknologi Tropika, 4(3), 180-190.

Mauidzotussyarifah, Aini, N., \& Herlina, N. (2018). Optimalisasi pemanfaatan lahan dengan pola tanam tumpangsari pada tanaman buncis (Phaseolus vulgaris L.) dan tanaman pakcoy (Brassica rapachinensis). Jurnal Produksi Tanaman, 6(2), 246-251.

Mursalim, I., Mustami, M. K., \& Ali, A. (2018). Pengaruh penggunaan pupuk organik mikroorganisme lokal media nasi, batang pisang, dan ikan tongkol terhadap pertumbuhan tanaman sawi (Brassica juncea ). Jurnal Biotek, 6(1), 32-42. https://doi.org/https://doi.org/10.24252/jb .v6i1.5127

Mutiara, C., \& Bolly, Y. Y. (2019). Identification of agricultural activities and soil fertility in the cultivation area of nuabosi cassava. Caraka Tani: Journal of Sustainable Agriculture, 34(1), 22. https://doi.org/10.20961/carakatani.v34i1 .25708

Nai, C. P., \& Fowo, K. Y. (2019). Respon pertumbuhan dan hasil tanaman jagung pulut (Zea mays ceratina kulesh) pada berbagai jarak tanam dalam baris. Agrica, 12(1), 58-69. https://doi.org/https://doi. org/10.37478/agr.v12i1.12

Pu'u, Y. M. S. ., Mutiara, C., \& Pande, Y. (2019). PKM-Kelompok tani alam Subur di Desa Nduaria Kecamatan Kelimutu Kabupaten Ende Nusa Tenggara Timur. Jurnal Abdimas Unmer Malang, 4(2), 4751. https://doi.org/https://doi.org/10.269 05/ abdimas.v4i2.3480

Pulupi, N. P. (2015). Ragam larutan mikroorganisme lokal sebagai dekomposter rumput gajah (Pennisetum purpureum). Ziraa'ah, 40(2), 123-128.

Rosliana, Sumarni, N., \& Sulastrini, I. (2010). Pengaruh cara pengolahan tanah dan tanaman kacang-kacangan sebagai tanaman penutup tanah terhadap kesuburan tanah dan hasil kubis di dataran tinggi. Jurnal Hortikultura, 20(1), 36-44.

Sankaran, K., \& Demangeot, C. (2017). Conceptualizing virtual communities as enablers of community-based entrepreneurship and resilience. Journal of Enterprising Communities: People and Places in the Global Economy, 11(1), 7894. https://doi.org/http://dx.doi.org/10.11 08/JEC-02-2015-0017

Secundo, G., Del Vecchio, P., Schiuma, G., \& Passiante, G. (2017). Activating entrepreneurial learning processes for transforming university students' idea into entrepreneurial practices. International Journal of Entrepreneurial Behavior \& Research, 23(3), 465-485. https://doi.org/ https://doi.org/http://dx.doi.org/10.1108/I JEBR-12-2015-0315

Septariani, D. N., Herawati, A., \& Mujiyo. (2019). Pemanfaatan berbagai tanaman refugia sebagai pengendali hama alami pada tanaman cabai (Capsicum annum L.). 3(1), 1-9.

Shahabuddin. (2012). Teknik pengendalian lalat buah Bactrocera sp. (diptera: tephritidae) pada pertanaman cabai menggunakan perangkap dengan isyarat kimia dan visual. Agroland, 19(April), 56-62.

Susanto, A., Natawigena, W. D., Puspasari, L. T., \& Atami, N. I. N. (2018). Pengaruh penambahan beberapa esens buah pada perangkap metil eugenol terhadap ketertarikan lalat buah Bactrocera dorsalis kompleks pada pertanaman mangga di Desa Pasirmuncang, Majalengka. Jurnal Perlindungan Tanaman Indonesia, 22(2), 150-159.

https://doi.org/10.22146/jpti.27001

Tambunan, E. P. S. (2018). Pengaruh konsentrasi mikroorganisme lokal limbah tomat dan limbah air kelapa terhadap pertumbuhan tanaman cabai (Capsicum annum L.). Klorofil, 1(2), 64-68.

Ulfa, A. N., Barokah, U., Fajarningsih, R. U., Sutrisno, J., \& Supardi, S. (2020). Peningkatan kapasitas usaha mina mandiri melalui pelatihan pemasaran produk olahan ikan. Prima Journal of Community Empowering and Services, 4(1), 1-6. https://doi.org/https://dx.doi.org/10.2096 1/prima.v4i1.37839 